\title{
A INOCÊNCIA DO MUSEU: INTERSECÇÕES ENTRE LITERATURA E ARTES VISUAIS
}

\author{
Emerson Dionisio Gomes de Oliveira ${ }^{\text {** }}$ \\ Universidade de Brasília
}

\section{RESUMO:}

O presente artigo buscou analisar a relação entre o romance "Museu da Inocência" e o museu homônimo, ambos criados pelo escritor turco Orhan Pamuk. A coleção criada por Pamuk para orientar na confecção do livro e as estratégias de torná-la visível foram os processos debatidos. Depois de um breve comentário sobre o museu, segue-se a comparação entre as estratégias museológicas e estéticas utilizadas por Pamuk e aquelas adotadas por artistas visuais desde os anos de 1960.

\section{PALAVRAS-CHAVE:}

Orhan Pamuk. Museu da Inocência. Arte contemporânea.Teoria crítica.

\begin{abstract}
:
This work seeks to analyze the relationship the novel "Museum of Innocence" and the homonym museum, both created by the Turkish writer Orhan Pamuk. The collection created by Pamuk to guide the making of the book and the strategies to make it visible processes were discussed. After a brief comment on the museum, we have a comparison between the museum and aesthetic strategies used by Pamuk and those adopted by visual artists since the 1960s.
\end{abstract}

\section{KEY-WORDS:}

Orhan Pamuk. Museum of Innocence. Contemporary art. Critical theory.

I * Doutor em História pela Universidade de Brasília. Docente do Departamento de Artes Visuais e do Programa de Pós-Graduação em Arte da Universidade de Brasília; docente do curso de Museologia na mesma instituição. 
Numa breve passagem do diálogo Fedro, Platão distingue recordação e memória. Para o filosofo, esses conceitos têm relação com a "interiorização" do conhecimento.A memória representa, de certa maneira, o saber. E não podia ser apreendida através de símbolos externos ao indivíduo, pelo contrário, era inerente a ele.A escrita permitia a criação de um processo mnemotécnico, no qual os símbolos externos proporcionam a quem leu a possibilidade de se recordar de determinado conhecimento. Essa recordação, em Platão, é distinta e inferior à memória advinda do tipo de conhecimento que o filósofo declarava ser o único verdadeiro, a saber: aquele que não pode ser ensinado, pois provém do interior do indivíduo. Sinais exteriores, dessa forma, não podem ensinar o que quer que seja. Os signos exteriores não significavam a verdadeira memória. A distinção platônica, embora superada, nos oferece uma excelente metáfora para a compreensão da dupla jornada do escritor turco Orhan Pamuk: a escrita do romance Museu da Inocência (PAMUK, 20I Ia), publicado originalmente em 2008, e a instauração do "Museu da Inocência", inaugurado em Istambul em 2012 (Figuras I e 2). Dentro do romance, um museu de adoração fetichista dos objetos "interiores" relacionados à mulher amada. Fora, um museu dedicado a rememorar, por meio de objetos "exteriores", uma narrativa ficcional: um museu do Museu.

As questões que se apresentam possuem um caráter inevitavelmente ordinário: um museu pode nascer de uma obra ficcional? Ou um romance pode ser concebido da vontade de construir um museu? Evidentemente que as respostas afirmativas não esgotam o problema no que concerne ao modelo ético que sustenta toda uma ideologia patrimonial no ocidente.l $O$ presente artigo busca debater como um museu pode ser concebido dentro de uma obra de arte e afetá-la de modo a constituir-se parte de sua própria poética.

O “Museu da Inocência”, instalado no bairro de Çukurcuma2, em Istambul, é uma operação complexa, na medida em que nos faz perguntar sobre os limites entre a memória, enquanto modalidade veritativa de uma dada comunicada, e uma memória ficcional, intima e particular, construída a partir de uma trama autorreferente, que tem em seu criador sua matriz instituidora. Para aprofundar nossas discussões, vamos percorrer o processo de criação da história de Kemal e Füsun e compreender quais elementos visuais e memoriais "exteriores" são explicitados, uma vez que Pamuk considera que, "sem dúvida, todo o texto literário se dirige, ao mesmo tempo, à nossa inteligência visual e à nossa inteligência textual." (PAMUK, 20I I b, p. 67). O enlace entre textualidade e visualidade aprofunda-se com a constituição do museu em 2012 e impacta, desde o início, seu projeto "curatorial" e expográfico. Proporemos, a seguir, uma leitura de como o jogo tramado por Pamuk relaciona-se com os modelos ficcionais e poéticos da arte contemporânea, área que especialmente nos interessa.

\section{Uma inacreditável história de silêncios}

Museu da Inocência conta a história de um amor frustrado, carregada de desencontros, interdições e silêncios. $O$ autor institui-se como personagem da

I "Que eu saiba, este é o primeiro museu baseado num romance", alerta Pamuk, em entrevista ao Jornal The New York Times. KENNEDY, J. Michael. Pamuk e a nostalgia. O Estado de São Paulo, São Paulo, 8 maio 2012. Caderno 2, D7.

$2 \mathrm{Na}$ transcrição dos nomes de origem turca, obedecemos aos tradutores para a língua portuguesa voltados ao mercado editorial brasileiro (Hildegard Feist e Sergio Flasksman), mesmo quando as fontes estão em língua inglesa e francesa. 

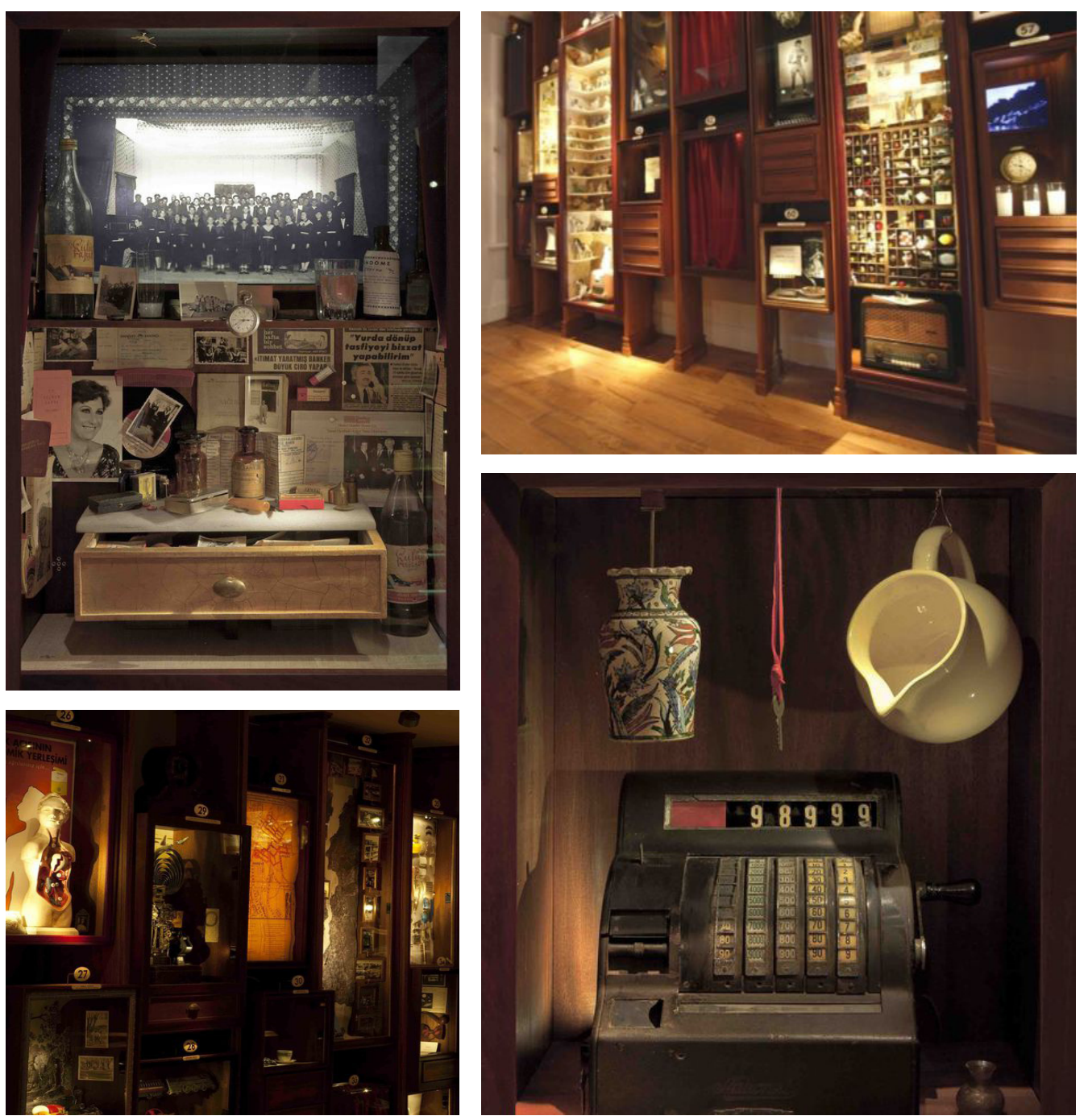

Figura I - Imagens do Museu da Inocência, inaugurado em Istambul em 2012. Fonte: MUSEU DA INOCÊNCIA. Site oficial do museu.

Disponível em: <www.masumiyetmuzesi.org>. Acesso em: nov. 2012.

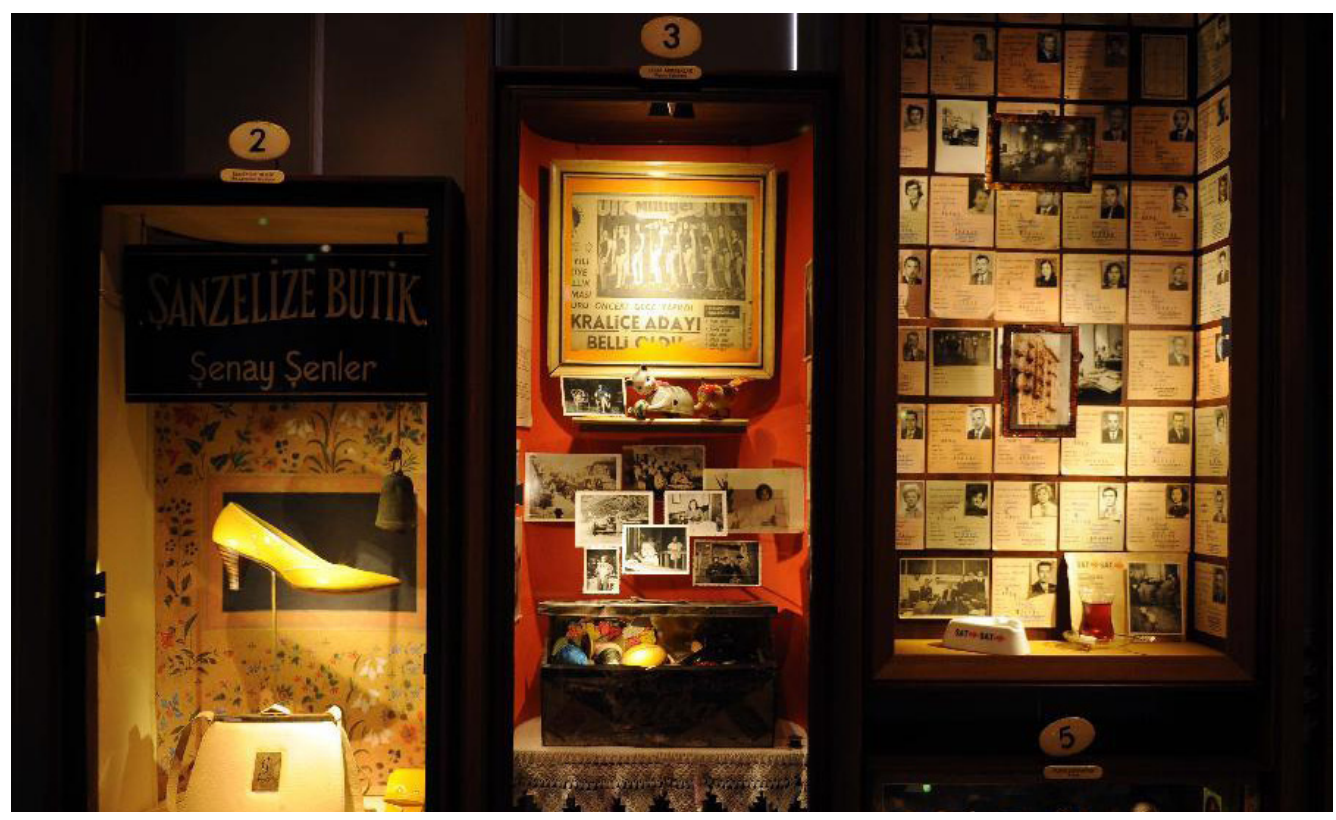

Figura 2 - Imagens do Museu da Inocência, inaugurado em Istambul em 2012.

Fonte: MUSEU DA INOCÊNCIA. Site oficial do museu.

Disponível em: <www.masumiyetmuzesi.org>. Acesso em: nov. 2012. 
narrativa num discurso memorial quase documental. Pamuk, o escritor contratado por Kemal, "herói” do romance, apresenta o drama do protagonista apaixonado por uma mulher mais jovem que ele, Füsun. É a história do lamento de um "herói" impotente diante de um destino que se apresenta mais forte que ele - o destino de um personagem frustrado, que amplia seu sofrimento por meio de narrativas enviesadas e mal-entendidos inexplicáveis. Kemal, o personagem, sofre pelo que realmente acontece; pelo que já aconteceu e pelo que imagina que poderá acontecer. Num sentido romântico, ele sofre principalmente pelo o que imagina e pelo que sonha. Sofre ao imaginar que sua amada está morta. Sofre ao imaginar que ela o abandonará. Sofre, principalmente, por amá-la.

A narrativa é fragmentada em oitenta e três capítulos que descrevem o envolvimento de Kemal com Füsun: o término do noivado de Kemal com Sibel (sua primeira noiva); o desaparecimento de sua amada (tema recorrente para Pamuk3), que consome páginas e páginas do romance; a decepção de reencontrá-la casada; as estratégias para aproximar-se de toda a família da moça por meio do marido; as incursões na incipiente indústria cinematográfica turca; a esperada união; e o fim trágico. Em sua perspectiva material, o museu surge, desse modo, como uma forma de recordação de uma impossibilidade e do sofrimento: o amor de Kemal e Füsun.4

O autor lembra recorrentemente que o livro foi escrito concomitantemente à vontade de criar um museu para a memória desse amor. $\bigcirc$ método que utilizou para escrever o romance é revelador de como livro e museu estão intrinsecamente relacionados. Pamuk acredita que a descrição de objetos, lugares, enfim, das coisas "externas" do mundo num romance deve ser a expressão da compaixão pelas personagens (PAMUK, 20 l lb, p 85). Ou seja, construir, pela narrativa, um espaço que delineie os sujeitos do romance e que deles faça parte. Ele se inspirou nos objetos que cercavam as personagens, ora encontrando-os antes de inseri-los na trama, ora percorrendo lojas, antiquários, brechós, mercados etc. em busca daquelas "coisas" que havia imaginado para seu romance:

Eu pretendia usá-los no romance e estava imaginando situações, momentos e cenas adequadas a esses objetos, muitos dos quais (como um ralador de marmelo) eu comprara por impulso. Uma vez, fuçando num brechó, encontrei um vestido de tecido claro com rosas alaranjadas e folhas verdes e decidi que era perfeito para Füsun, a heroína de meu romance. Com o vestido estendido diante de mim, pus-me a escrever os detalhes de uma cena em que Füsun, usando esse exato vestido, está aprendendo a dirigir. (PAMUK, 20l lb, p. 88-89)

\footnotetext{
30 autor dedica especial atenção ao tema em O livro negro, obra publicada originalmente em 1990, na Turquia. Nele já podemos encontrar traços do leitmotiv do Museu da Inocência:

Em algum ponto dessas novas procuras baldadas, quando se via tendo nas mãos a caixa vazia de um par de óculos escuros havia muito perdido ou às voltas com as memórias despertadas pela fivela de um dos velhos cintos de Rüya, ele entendia como tudo aquilo era em vão e sem sentido (e como eram implausíveis os detetives de todos aqueles livros, para não falar dos autores compassivos que sussurravam pistas oportunas nos ouvidos dos seus heróis!), e então devolvia o objeto que tinha nas mãos ao seu lugar de origem - com uma precisão meticulosa, com o cuidado do pesquisador que elabora o inventário de um museu - e voltava para cozinha a passos de sonâmbulo. (PAMUK, 2008, p. 66).

4 Uma dimensão não explorada do romance aqui diz respeito a seu elo com a cidade e à cultura local.A história do romance percorre o último quarto do século passado e apresenta-nos um impressionante retrato do cotidiano das famílias de classe média de Istambul. Do mesmo modo, todo o romance funciona como um retrato dos tensos dilemas que envolvem uma sociedade instaurada entre o Oriente Médio e o Ocidente: “(...) o que temos aqui não é uma simples história de amor, mas de todo o reino, ou seja, de Istambul." (PAMUK, 20l la, p. 555). Pamuk dedicou um livro exclusivamente à sociedade e à história da cidade (2007).
} 
Esse caminho, que levou o autor a uma coleção particular de objetos destinados à elaboração do livro e à constituição do acervo do museu, foi fartamente explorado no romance. Os objetos passaram a ser marcadores da obsessão de Kemal em preservar a memória de seu amor por Füsun. Como o escritor, o protagonista utilizou os mais variados processos para colecionar as peças do futuro museu que, no final do livro, ele abriria (o livro antecipa em quatro anos a inauguração efetiva do museu). Comprar, trocar, furtar, negociar foram modos de construir o acervo que tinha como objetivo inicial, para o protagonista, de reter o passado. Guardar os momentos prazerosos e fugazes com sua amada Füsun. De modo singular, Pamuk-Kemal realiza uma espécie de "antropologia da materialidade”, numa acepção própria oferecida por Appadurai (2010): cada objeto transforma-se num complexo elo entre narrativas distintas, imaginação e um conjunto mais amplo de materialidades. 5

O livro salienta recorrentemente o colecionamento. Coleção, ao lado de um sentido abstrato de "público", é possivelmente o conceito museológico mais explorado pelo escritor. $O$ romance esmiúça três dimensões particulares e interconectadas do processo de colecionar.A primeira está diretamente ligada ao tradicional sentido de posse aurática, própria da relíquia, cuja função é servir como pedaço autêntico do passado:

Tantas línguas descrevem a condição em que me encontrava como 'coração partido' que o coração quebrado de louça aqui exponho deve bastar para descrever aos visitantes do museu o que senti naquele momento. (PAMUK, 20I la, p. 292).

Todavia, romance e museu rompem com a dinâmica da relíquia moderna: a autenticidade como valor essencial para apresentar o passado.6 Os objetos colecionados no romance e mostrados no museu não se autenticam pela experiência factual. Muitos dos objetos expostos são clones, cópias de objetos com atributos equivalentes. A autenticidade daquilo que é possuído está depositada na narrativa ficcional e na lógica expositiva do museu.

Complementar a essa dimensão possessiva do passado é aquela que significa a coleção como legado, herança 7. Um conjunto de objetos dotados da qualidade de preservar, para as futuras gerações, as qualidades e os valores do

5 Em entrevista concedida em 2008, o antropólogo indiano amplia sua abordagem sobre a vida material, inscrita no clássico A vida social das coisas (EdUFF, 2008), integrada à força social da imaginação:

Elaborei a idéia da imaginação como fato social no início dos anos 90 , que culminou nas afirmativas que fiz em 1996, em Modernity at Large, no qual a imaginação constituiu, talvez, a ideia central ou motriz. Nessa época, não tinha consciência da conexão dessa idéia com A vida social das coisas, mas você está totalmente correta em dizer que, então, eu já não queria ver a imaginação como uma faculdade individual, ou, se quiser, mental, ou como algo separada de efeitos sociais. Eu já estava, creio, tentando enxergar como a imaginação se materializava. (APPADURAI, 20 I0, p. 190).

6 Lembramos o seguinte:

O senso comum atribui ao museu uma ligação com o que é autêntico e original. Consequentemente, à preservação da memória, como se o que foi recolhido, guardado, estudado e exposto fosse, a rigor, o primordial, o inesquecivel. Estende-se à memória a concretude dos componentes físicos do objeto museológico ou, dizendo de outra forma, como se o objeto contivesse em si a memória do que revela, o distingue, o singulariza. (CASTRO, 2009, p. 26).

7 Dentro da tradição francesa, de grande influência para além das fronteiras nacionais, Poulot identificou o final do século 18 como o momento crucial para que a transmissão dos bens se tornasse uma característica essencial do próprio sentido de patrimônio:

A nova economia moral dos objetos e das obras insere-se no princípio de uma preservação minuciosamente estudada.A transmissão 'à posteridade' é doravante o resultado de iniciativas bem pensadas, expressamente desenvolvidas para esse efeito, e não o fruto do acaso. É uma nova representação do passado que se tenta forjar através de uma judiciosa distinção do insignificante a ser apagado, ou do memorável a ser instaurado ou, às vezes, a ser reconduzido, mas sempre em nome da reabilitação do autêntico. (POULOT, 20I I, p. I6). 
passado experimentado. Nesse tocante, a coleção apresenta-se como uniforme. Objetos de todas as ordens, utilidades, procedências e datações são interpretados como tendo uma única finalidade temporal:

Minha vida me ensinou que lembrar-se do Tempo - a linha que conecta cada momento que Aristóteles chama de presente - é, para a maioria de nós, um exercício doloroso. Quando tentamos imaginar a linha que conecta esses momentos, ou, como em nosso museu, a linha que conecta todos os objetos que trazem esses momentos dentro de si, somos forçados a lembrar que a linha chegará a um fim, e contemplar a morte. (...) Desde o início, sabia que só estava indo à casa dos Keskin na esperança de poder reunir felicidade suficiente para durar até o fim da minha vida, e era na intenção de preservar para o futuro esses momentos felizes que eu recolhia tantos objetos, grandes e pequenos, que tinham passado pelas mãos de Füsun, e os levava para casa. (201 la, p. 309-310).

Essa é uma perspectiva em que se pensa o passado, contido na materialidade objectual, prioritariamente com olhos do passado, portanto como algo imutável, e em que se esforça para que qualquer interpretação identifique-se com uma narrativa primeira e autorizada.

A terceira dimensão explorada por Pamuk diz respeito ao propositor da coleção: o colecionador. A coleta, a seleção, a guarda e a conservação dos objetos ganham sentido graças àquele que os reúne.A percepção do colecionador é distinta ao logo do livro. Primeiro, o narrador se vê como um colecionador autêntico, despreocupado, pois, quando reúne "seus primeiros objetos, quase nunca se pergunta qual será o destino final de seu tesouro" (PAMUK, 20I la, p. 87). Para Kemal-Pamuk, os colecionadores genuínos eram aqueles que "nunca reconheciam o valor real desses artigos" (idem). Depois, quando o protagonista passa ativamente a negociar os objetos no intuito de construir o museu, o colecionamento adquire tons próprios da assimilação, aquisição e complemento. Os objetos ganham finalidade unívoca. Inúmeras vezes Kemal-Pamuk cita outros colecionadores de quem adquiriu objetos complementares ao acervo reunido. Como quando adquire cartazes e fotografias de filmes produzidos em meados dos anos de 1970 para expô-los ao lado dos canhotos dos ingressos assimilados anteriormente (PAMUK, 20I la, p. 28I). A autenticidade repousa no discurso museológico e não na "experiência dos objetos".

A dimensão do colecionador autêntico em Pamuk assemelha-se àquela defendida por Walter Benjamin. Ele positiva o ato do colecionamento como aquele capaz de retirar o uso ordinário dos objetos, dotando-os de outros significados. "É decisivo na arte de colecionar que o objeto seja desligado de todas as suas funções primitivas" (BENJAMIN, 2006, p. 239)8. O verdadeiro colecionador é, portanto, aquele que insere o objeto específico em um círculo pessoal de sentidos, o que não significa alienação, pelo contrário, cada objeto da coleção está diretamente ligado à rememoração de sua história passada, seus usos anteriores, aqueles que os possuíram (BENJAMIN, 1987, p. 228).

Nesse sentido, é sintomático lembrar que o escritor passa anos dedicados a visitar outros museus, atitude que transfere para seu protagonista, que também se dedica a conhecer distintas formas de coleção. A visita a centenas de museus pelo mundo não deixa de evidenciar o colecionador de percepções

8 Benjamin questiona-se de que os livros são os únicos que mantêm sua função dentro de uma coleção (2008, p. 24I). Podemos ampliar essa excepcionalidade para parte considerável da arte produzida no último século. 
sobre outras coleções. Mas o que elas guardavam em comum com o "Museu da Inocência" inaugurado em 2012? Se o romance for um bom mapa, e acreditamos que seja, para além dos museus de personalidades e históricos, o que liga os museus enumerados no octogésimo primeiro capítulo é sua incessante necessidade de conviver com elementos cotidianos e banais das memórias preservadas e apresentadas. Muitos desses museus buscam perpetuar memórias deixadas à margem das grandes narrativas ou dos circuitos midiático-turísticos convencionais. "Meu romance honra os museus aonde ninguém vai, aqueles nos quais você pode ouvir o som dos seus próprios passos" (PAMUK apud MELENDI, 20I2, p. 8I). Museu Nissim de Camondo, Museu Jacquemart-André, Museu do Serviço dos Objetos Esquecidos, Museu Postal, Museu da Cidade de Cazalles, Civico Museo del Mare, Museu das Mariposas e outros insetos, Museu da Medicina Chinesa, Museu do Forte de São Jorge são alguns exemplos dos museus visitados. É evidente que, individualmente, cada um desses museus tem peso e impacto distinto em suas comunidades, mas, reunidos no livro, como uma coleção de museus visitados, eles funcionam como norteadores das ambições museológicas de Kemal. Nesses museus, o personagem pode compreender a variedade do que se pode colecionar e a importância de comunicá-las.

Passear por esses museus de Paris era ser libertado da vergonha da coleção que eu acumulava no apartamento de Merhamet. Deixando de ser um seu jeito esquisito, envergonhado pelas coisas que empilhava, eu aos poucos adquiria o orgulho de um colecionador. (PAMUK, 201 la, p. 524).

Não deixa de ser exemplar que uma visão benjaminiana do ato de colecionar seja perceptível no romance. Como uma forma de recordação, a coleção torna-se uma prática contra a dispersão e o apagamento. Pamuk/Kemal são colecionadores dedicados a uma luta incessante contra uma das facetas inevitáveis da memória: o "esquecimento". Não do esquecimento da própria estória de amor vivida em Istambul, delicadamente narrada no livro, mas sentinelas das recordações que unem todos os objetos díspares reunidos no museu. Enquanto - livro instaura o elo que os ata à história, o museu busca conservá-lo. Com - museu, o drama literário não cessa de renascer do distanciamento em que consiste a exterioridade do rastro que ele conserva. $O$ autor está intensamente preocupado em mostrar menos a relação representacional que une os dois romance e museu - e mais sua condição de arquivo:

A qualidade 'museologizante' em que gostaria de me demorar está menos em suscitar pensamentos e mais em preservar, conservar e resistir ao esquecimento.Assim como famílias que vão a um museu no domingo, achando que ele preserva algo de seu próprio passado e tendo prazer com essa ideia, os leitores também têm grande prazer em descobrir que um romance incorpora facetas de sua vida real - a parada de ônibus no fim de sua rua, o jornal que eles leêm, o filme que eles amam, o sol poente que contemplam de sua janela, o chá que eles tomam, (...). A razão para essa felicidade talvez seja semelhante à ilusão e ao orgulho subsequente que sentimos num museu: a sensação de que a história não é oca e desprovida de significado e de que alguma coisa da vida que vivemos será preservada. (PAMUK, 20l l b, p. 99)

Nas obras do escritor, museu e romance, o que reencontramos é compreensão do arquivo enquanto sinais e resquícios do processo de criação autoral. Uma forma de salvaguardar não apenas o interior da narrativa, seja pela 
escrita, seja pela expografia, mas, sobretudo, de conservar o processo de criação do próprio escritor. Ulpiano Meneses chama atenção para o fato de que os profissionais do arquivo (museólogos, historiadores, arquivistas, bibliotecários, conservadores etc.) negligenciam o poder dos arquivos materiais e virtuais dos artistas, na medida em que ignoram seu impacto em suas poéticas $(2010$, p.I I). Nesse tocante, a tensão entre o romance e o museu se instaura dentro de um comparativo modelo de pressuposições: o que nos revela o museu sobre o romance e o quanto o romance serve como guia para a compreensão do museu. $\mathrm{O}$ embate entre dois modelos discursivos distintos se estabelece. Essa tensão está próxima do sentido derridiano de arquivo, baseado no conflito entre sua dimensão memorial e seu inevitável vínculo com o lugar de lei, da autoridade de um outro (DERRIDA, 200 I, p. 32).

O processo de tradução é complexo e concomitante. Trata-se de dois operadores memoriais distintos. O literário não se rende às premissas basais do veritativo, seu compromisso é com sua própria estrutura narrativa, e seu elo com mundo exterior é tão tênue quanto inevitável. Já o discurso museal obedece à instauração de uma autoridade, no sentido que Certeau confere ao termo: representações ou pessoas que se querem aceitas como críveis (CERTEAU, 1995, p. 40). O museu faz crer o romance, ou ao menos assim o pretende. Sendo assim, as dimensões simbólica e ética do museu e do romance não se equivalem; já nascem distantes. Pelos limites de um enquadramento pedagógico e um compromisso social, o museu subordina-se ao romance que the dá forma. A exterioridade das coisas nele contidas depende da materialidade textual e visual do romance. No entanto, há uma outra forma de abordar a questão: o museu como uma grande instalação, uma obra poética em si.

\section{0 museu como instalação}

Dentre as inúmeras direções tomadas pelas artes visuais desde o final dos anos de 1950, destacam-se dois fenômenos interdependentes que marcaram a ascensão da arte contemporânea nas duas décadas subsequentes. $O$ primeiro foi a expansão do sistema da arte: a inserção da arte atualizada num mercado global, a expansão do colecionamento para além das instituições convencionais, a ampliação dos modelos de difusão, a instauração do curador como mediador privilegiado e a criação de novos museus de arte contemporânea, devotados tanto à memória quanto à experimentação. $O$ segundo foi o surgimento de um amplo e difuso processo poético baseado na crítica e no combate ao mesmo sistema da arte 9. Brandon Taylor (1995, p. 105-106) divide os artistas dedicados a essa poética em dois grupos: aqueles que confrontaram as instituições da arte com estratégias inócuas, que foram imediatamente absorvidas pelo sistema que pretendiam julgar (Carl Andre, Richard Long, Joseph Kosuth, John Hilliard, Gilbert e Georg, Ed Ruscha e Jan Dibbets segundo o autor), e aqueles que realmente colocam em xeque o modelo operacional da rede internacional de legitimidade da arte. Para esse segundo grupo,Taylor não lista nomes, mas podemos indicar artistas como Marcel Broodthaers, Graciela Carnevale, Daniel Buren Andrea Fraser, Guerrilla Girls, Umberto da Costa Barros, Silvia Kolbowski, Hans Haacke, Michael Asher, Lea Lublin,Artur Barrio, entre tantos outros.

9 A faceta mais conhecida dessa tendência foi aquela que reuniu artistas europeus e estadunidenses sob a difusa rubrica de Crítica Institucional; cf. FRASER,Andrea. From the critique of institutions to an institution of critique. In:WELCHMAN, John C. (ed.). Institutional Critique and After. Zurique:JRP Ringier, 2006, p. I22-I 35. 
Independentemente dessa severa divisão de Taylor, a arte, a partir dos anos de 1970, passou a questionar seu próprio valor e lugar. De um elenco diverso de criadores ocupados com esse questionamento, é possível destacar artistas que transformaram o museu em elemento de manejo poético. De um modo amplo e raramente sistemático, artistas atuaram sobre todas as práticas museológicas: criticaram e se apropriaram dos processos curatoriais, mimetizaram desenhos expositivos, evidenciaram práticas de colecionamento, escrutinaram procedimentos de conservação e restauro, intervieram em ações educativas etc. Algumas dessas ações poéticas criaram e recriaram espaços museológicos em ações que comumente denominamos de instalações ou intervenções.

Dentro dessa perspectiva, talvez o mais notável projeto tenha sido aquele instaurado por Marcel Broodthaers. $O$ artista belga não foi necessariamente o pioneiro nos questionamentos às instituições da arte. Contudo, seu papel é crucial para a compreensão dessa tendência, uma vez que seu trabalho questionou profundamente os valores do colecionamento e o sistema expositivo. Quando Broodthaers, em 1968, apresenta a "Seção do século XIX" do Museu de Arte Moderna (uma contradição evidente e um crítica indicativa do modelo "evolutivo" da narrativa dos museus de arte), instalado em seu apartamento, o artista inicia o processo que propõe questionar o lugar da arte na sociedade a partir de um museu fictício. Ele apresentará, nos anos seguintes, uma infinidade de leituras e desdobramentos de seu museu "virtual" (Figura 3).

Broodthaers manipulou, em suas instalações, os rituais próprios das instituições museais - convites, folders, press-releases, mapas, sinalizações, projetos expositivos, souvenires, modelos curatorias (não tão evidentes na época), reservas técnicas e táticas de marketing -; mirou na aliança entre o discurso museológico e a história da arte, os quais, para ele, juntos criaram uma pedagogia que produziu tanto um discurso taticamente sintético e eficiente na intenção de fazer circular obras, valores e discursos de e sobre a arte, quanto discursos obscuros, cheios de lapsos e esquecimentos (SCHULTZ, 2007).

Todo o sistema de apresentação e mediação das obras foi questionado.Vitrines, painéis, catálogos, etiquetas, visitas monitoradas, vídeos "educativos", biografias fictícias, enfim, exposições e museus inteiros foram criados para apontar as contradições do sistema da arte. Em 1965, Claes Oldenburg planejou seu museu de objetos comuns, intitulado Mouse Museum, projeto que se estendeu até meados dos anos de 1970 e que se tornou um conjunto de instalações de objetos kitschs inspirados na figura do personagem da Disney (Figura 4).

Outro exemplo foi o museu de gavetas (Museum of drawers) de Herbet Distel, executado entre 1970-1977. Uma instalação destinada a comentar e criticar os compartimentos que unem o discurso museológico, a exaltação biográfica e a história da arte convencional. Nela, Distel apresenta miniaturas de obras de diferentes artistas. Todas devidamente compartimentados (Figura 5). Já Annette Messager expõe sua compulsão por álbuns de noivas - ficções - em inúmeras vitrinas perfiladas na Städtiche Galerie de Munique, em 1973, na instalação chamada Album Collections. Em 1970, Joseph Beuys expõe sua "constelação de ideias", uma miríade de objetos e obras produzidas ao longo de dez anos, no Hessisches Landemuseum, na pequena cidade alemã de Darmstadt, num arranjo espacial onde as vitrines esculpidas pelo artista e os displays são parte constitutiva e indissociável da instalação denominada Beuys Block: view of room 3. 


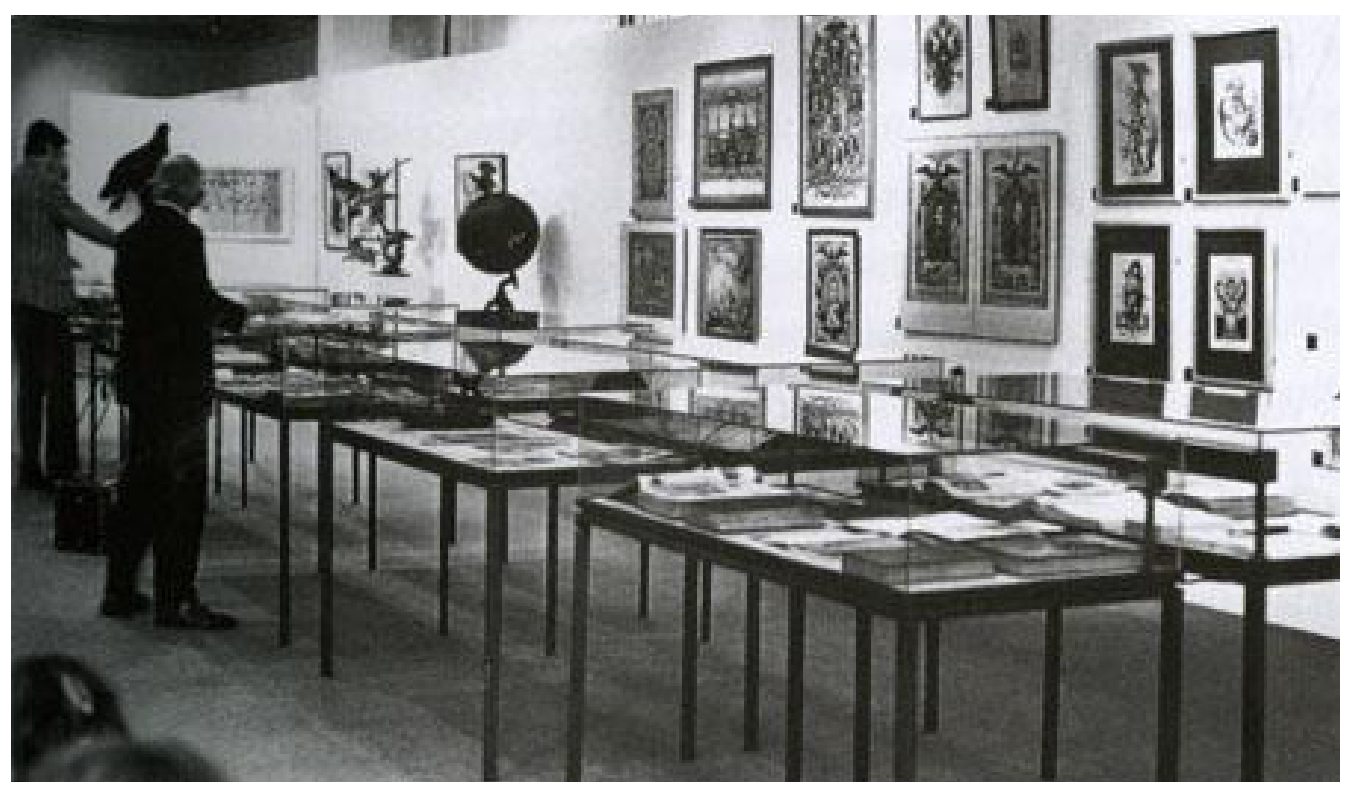

Figura 3 - BROODTHAERS, Marcel.

Museu de Arte Moderna, Departamento de Águias, seção de figuras.

Düsseldorf: Städtische Kunsthalle, 1972.

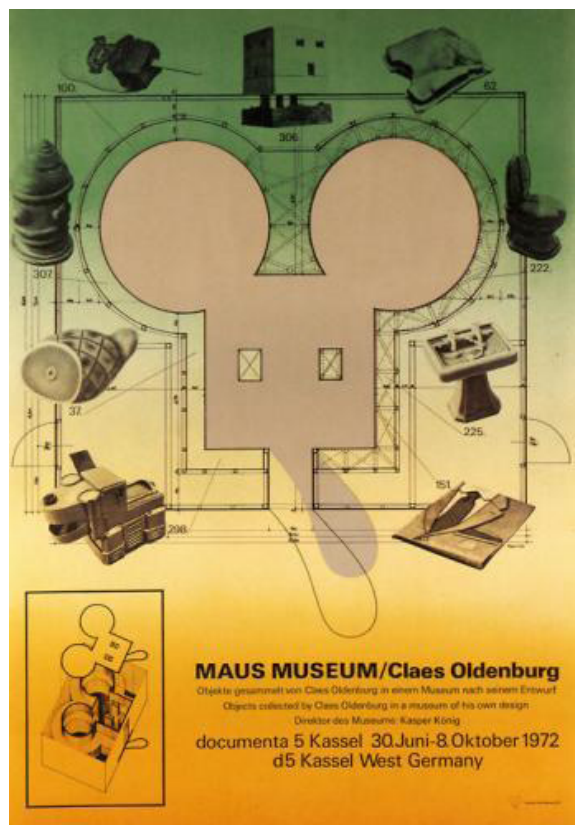

Figura 4 - Poster do Mouse

Museum de Claes Olderburg,

realizado para a V Documenta de Kassel em 1972.

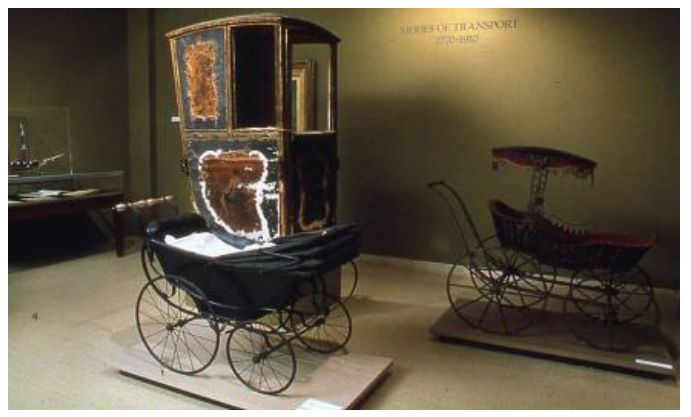

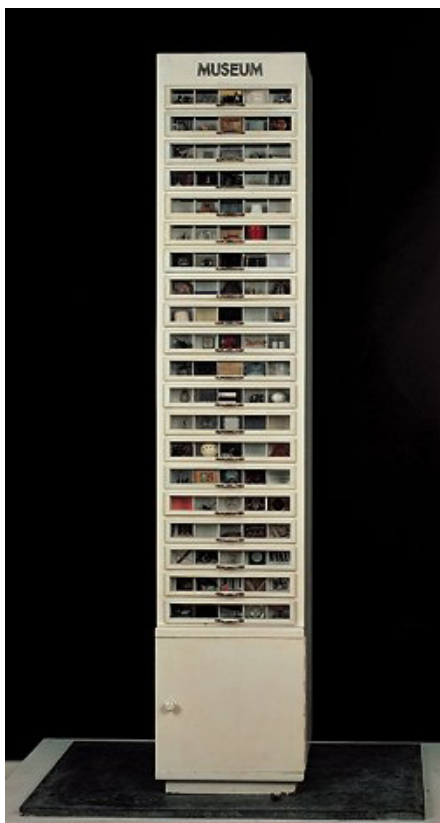

Figura 5 - DISTEL, Herbet.

Museum of drawers: instalação. Kunsthaus, 1970-1977.

Disponível em: <www.moma.org> Acesso em: nov. 2012.

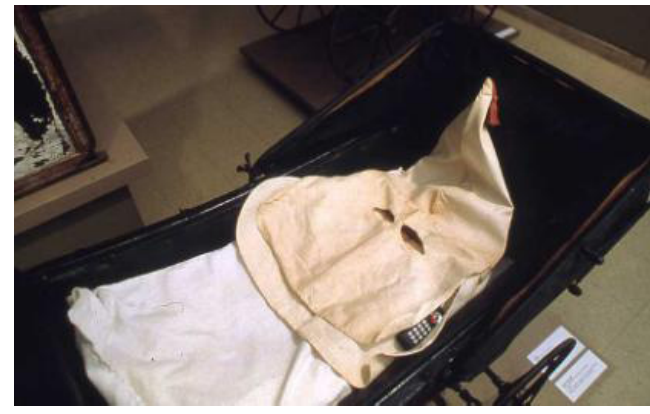

Figura 6 - WILSON, Fred. Modos de Transporte I770-1910: instalação,

1992-1993: parte da mostra Mining the Museum. The Contemporary and Maryland Historical Society. Fonte: Putnam, 2009. 
$\mathrm{Na}$ lista dos criadores que utilizaram objetos cotidianos como elementos matriciais de suas instalações, temos nomes como Andy Warhol, Daniel Spoerri, Georgia Starr, Peter Blake, Sophie Calle, Ross Sinclair I0, Mark Dion, entre tantos outros. Spoerri, por exemplo, criou, entre 1977 e 1989, quatro museus. Um projeto denominado Museu Sentimental, cujas coleções reuniram uma série de objetos ordinários vinculados à percepção que o artista possuía das cidades que acolhiam o projeto (PUTNAM, 2009, p. 24). As exposições negavam qualquer processo de ordenação tradicional. Funcionaram como uma caótica Wunderkammer contemporânea.

Há também artistas que trabalharam apropriando-se das coleções existentes e intervindo sobre elas: Richar Wentworth, Joseph Kosuth, Hans Haacke, Christian Philipp Mueller, Fabiano Gonper, Sarah Lucas, Jorge Pardo, entre outros. Fred Wilson, por exemplo, rearranja a exposição permanente do Museu da Sociedade Histórica de Maryland em 1992. Sua mostra, apropriadamente chamada de "Mining the Museum", cavou, no acervo do museu, elementos que não apenas demonstravam o conservadorismo dos museus históricos, mas que também expunham os procedimentos museológicos (em especial o projeto curatorial) como decisões políticas nada abstratas. A obra funcionou como um site-specific que apenas utilizava a própria coleção da instituição (Figura 6). Sua apropriação da coleção lembra a recriação realista de Claudio Costa, na instalação Museum of Man, de 1974, cujo modelo eram as cabeças e ossadas dos “homens primitivos”, numa ácida crítica à antropologia física e sua institucionalização por museus de ciência ocidentais.

Táticas expográficas também foram essenciais nesse processo. Se algum visitante do "Museu da Inocência" em Istambul estranhar as baganas reunidas e etiquetadas por Pamuk-Kemal para lembrar a cumplicidade com sua amada após um jantar, o sexo ou um passeio de carro, este mesmo visitante poderá recorrer a Dead ends died out, expored de Damien Hirst, obra de 1993, cujo processo de criação ampara-se na taxionomia do objeto-testemunho serializado (Figuras 7 e 8 ).

A seriação é um dos recursos obsessivos de Pamuk na constituição de seu museu. Objetos, fotografias, bilhetes repetidamente enfileirados, como prova do tempo e da persistência amorosa. A mesma obsessão que impulsiona artistas contemporâneos a perfilar sobre os olhos do público instalações como Between Taxonomy and Communion, de Anna Hamilton, criada em 1990.I I A artista expõe nela cerca de 14 mil dentes humanos e de animais, ordenadamente dispostos em grandes vitrines (Figura 9). Ou, ainda, Toothbrushes, de Karsten Boot, uma instalação de 1991 com centenas de escovas de dente usadas, dispostas lado a lado, bem ao gosto do museu de Pamuk.

Outros exemplos podem ser elencados para a compreensão do modelo expográfico adotado pelo Museu da Inocência. As oitenta e três vitrines numeradas, apresentadas no museu, configuram cada uma delas um capítulo do museu, numa reconstituição paulatina do romance. No capítulo "Algumas verdades antropológicas implacáveis", Pamuk adverte:

10 A crítica à mercantilização da obra de arte e o fetichismo narcisista do artista inspiraram Sinclair a criar o "Museu do Desespero" em 1994, onde vendia camisetas, fotografias, gravuras, pôsteres com suas obras (PUTNAM, 2009, p. 78).

II Muitos artistas dedicaram-se a mostrar elementos seriados numa perspectiva poética apoiada no colecionamento: Christian Boltanski, Tom Friedman, Allan McCollum, Nelson Leirner, Ed Burtynsky, Peter Greenaway, Sophie Calle, Mabe Bethônico, Carmela Gross, Susan Hiller,Tim Head, Rinko Kawauchi, Christian Marclay, Rivane Neuenschwander, Bil Lühmann, Andreas Siekamann, Daniel Buren, Annette Messager, Jac Leirner, Mark Dion, Arthur Bispo do Rosário, entre muitos outros. 


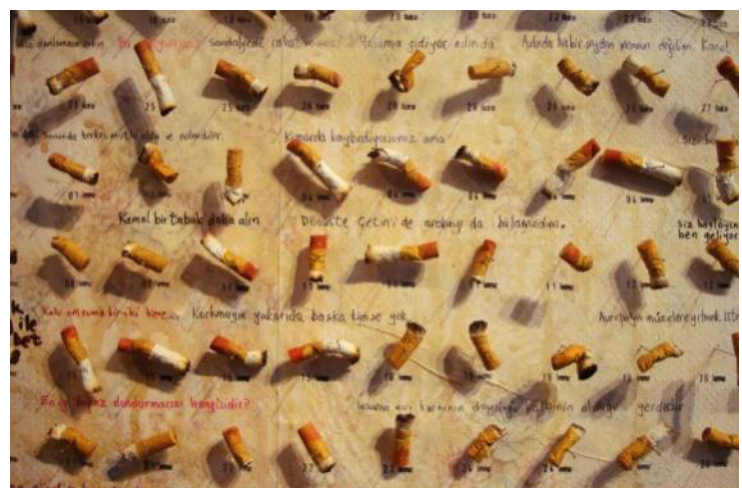

Figura 7 - Foto do Museu da Inocência.

Disponível em: <www.masumiyetmuzesi.org>. Acesso em: dez. 2012

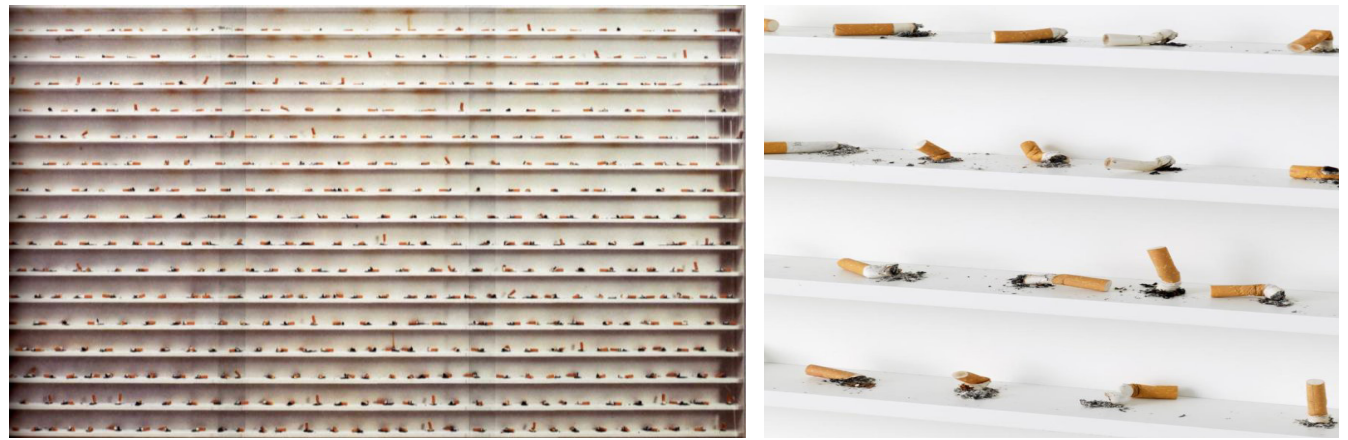

Figura 8 - HIRST, Damien. Dead ends died out, explored: instalação, 1993.

Retrospectiva do artista na Tate Modern de Londres, em 2012.

Fonte: Putnam, 2009 (detalhes).
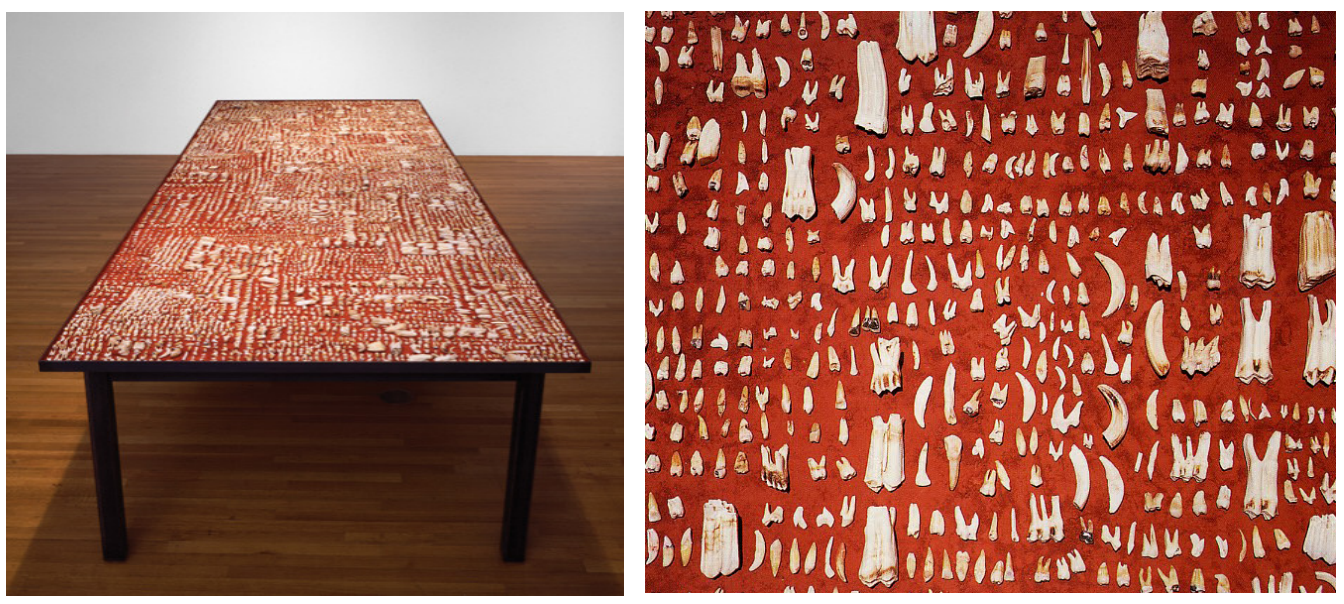

Figura 9 - HAMILTON, de Anna. Between Taxonomy and Communion: 1990/ 1996, instalação. Fonte disponível em:<http://www.guggenheim.org/new-york/collections/>.

Acesso em: dez. 2012. 
Tendo tocado na questão da 'sujeição', gostaria de retornar a um tema que se encontra na base do meu relato. Muitos leitores e visitantes já terão entendido perfeitamente do que se trata, mas, imaginando que gerações muito posteriores - como, por exemplo, as que visitarão nosso museu depois de 2100 - possam julgar o termo obscuro, deixo agora de lado o medo de me repetir e enuncio aqui uma série de verdades cruéis: no passado, a palavra preferida teria sido 'impalatáveis'. Mil novecentos e setenta e cinco anos solares depois do nascimento de Cristo, nos Bálcãs, no Oriente Médio e nas margens ocidentais e meridionais do Mediterrâneo, assim como em Istambul, a cidade que era a capital de toda essa região, a virgindade ainda era considerada um tesouro que as moças deviam proteger até o dia do casamento. (20I la, p. 75, grifo nosso)

O que se segue são seis consequências para "uma jovem que abrisse mão da castidade antes do casamento". O modo como o escritor resolveu expor o tema merece atenção por um motivo: é um dos raros capítulos em que não estão contidos "objetos" ligados à trama central do romance. No museu, observam-se, na vitrine, I 5 fotos perfiladas de mulheres de diferentes idades. Seus olhos são ocultados (Figura 10).As fotos representam vítimas do julgamento social, segundo Pamuk. Todavia, o modelo expográfico liga essa sessão a toda uma estética da arte política, preocupada em evidenciar dramas pessoais e coletivas.

Esse é um tipo de relato que incomoda. As fotografias funcionam como elementos que personificam, no coletivo e de modo anônimo, a violência sofrida pelas mulheres turcas. Justamente o tipo de discurso que incomoda os setores conservadores do país e que já renderam a Pamuk problemas jurídicos. Aqui, a vitrine nos lembra outro grupo de artistas (Glenn Ligon, Kara Walker, Doris Salcedo, Keith Piper, Rosangela Rennó (...) - a lista é longa), dedicados à memória da violência social. Artistas dedicados a criticar a velha crença de que o belo, o bem e a verdade se superpõem. $A$ vitrina $n^{\circ} 15$ guarda semelhanças, por exemplo, com Parede da Memória, de 1994, uma contundente crítica autobiográfica ao apagamento da memória das famílias afro-brasileiras realizada por Rosana Paulino. Do mesmo modo que a vitrina assemelha-se, enquanto poética, aos trabalhos de Cristian Boltanski dedicados às vítimas da Shoah. Trabalhos que muitas vezes são expostos de modo a reproduzir o discurso expográfico de museus históricos, como é caso de Vitrine de Referência, de I97I (Figura II).

Sabemos que acervos, muitas vezes, contribuem para a legitimidade de um dado discurso de verdade, apto a ser transmitido e que, geralmente, está amparado, de alguma forma, numa mitologia das origens. É justamente a narrativa dessa "mitologia" que muitos desses artistas acabam perturbando, dando-nos condições de percebê-las como construções políticas. $O$ museu de Istambul, ancorado num romance, também passa a perturbar as narrativas "inequívocas" e aparentemente neutras do discurso museológico convencional. Entretanto, encará-lo como uma grande instalação, dentro dos códigos especializados das artes visuais exige re-enquadrá-lo numa perspectiva política-estética diversa. Ele deixa de ser suporte do romance, como alentamos anteriormente, e passa a ser resíduo de uma "estrangeridade" da poética literária. Um "estrangeiro" com sua própria língua e consciente de que a tradução que deseja expressar a transferência de significado nunca pode ser total, nem desejável. 


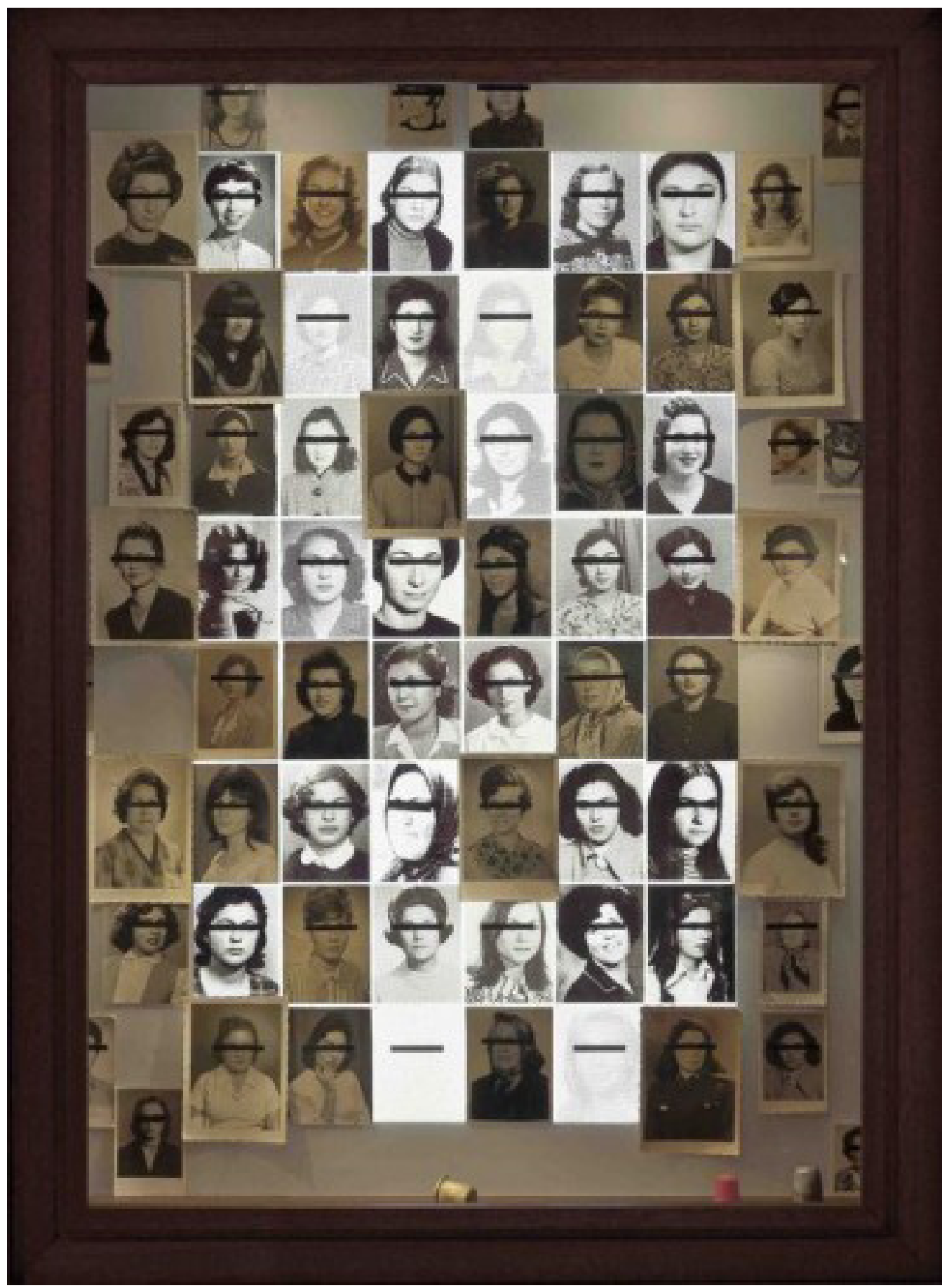

Figura 10 - MUSEU DA INOCÊNCIA.

Vitrina $n^{\circ} 15$, capítulo: algumas verdades antropológicas implacáveis.

Fonte disponível em: <observatory.designobserver.com>. Acesso em: dez. 2012. 


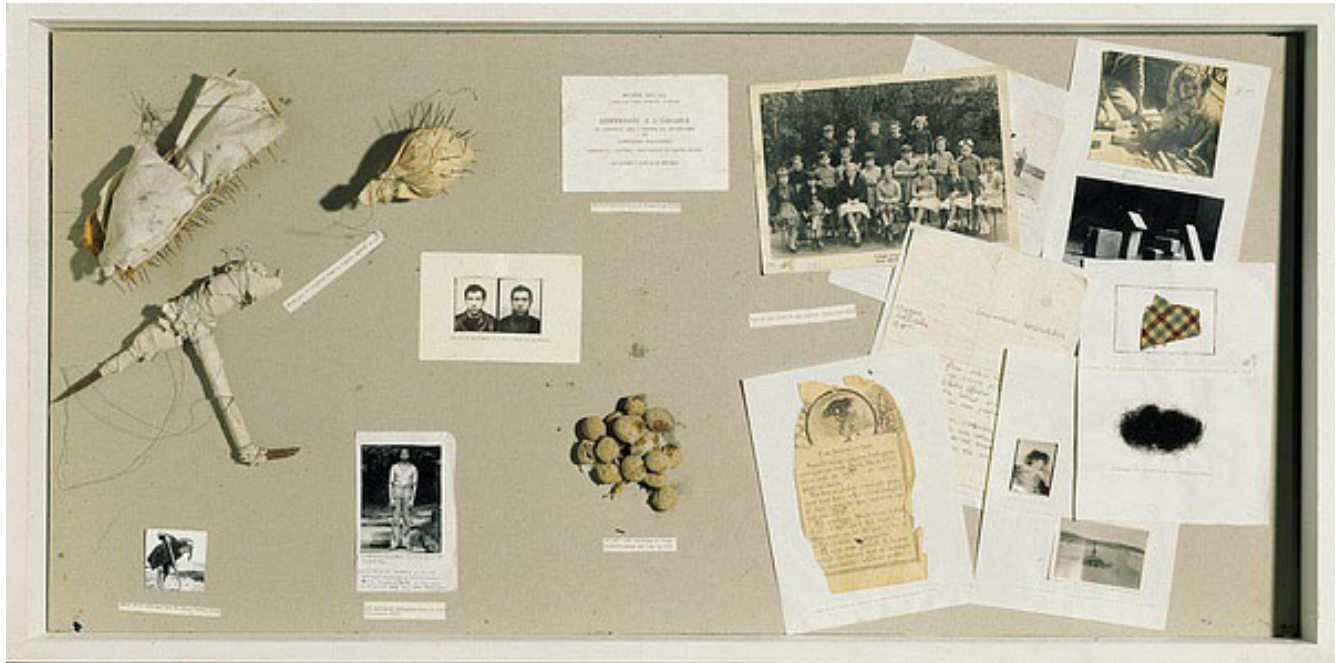

Figura II - BOLTANSKI, Christian.Vitrine de referência: I97I, instalação.

Fonte disponível em: <http://mediation.centrepompidou.fr/education/>.

Acesso em: dez. 2012.

- E onde pomos o bilhete?

- Aqui mesmo, claro!

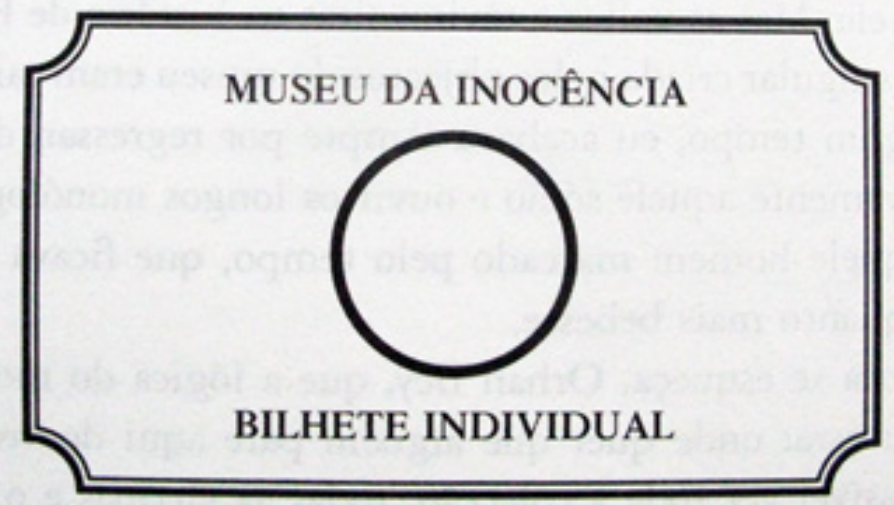

Figura 12 - $O$ bilhete de entrada do museu. Fonte: Pamuk, 20I la, p. 550. 
O alvo dessa tradução passa a ser o próprio artista. O museu usa a linguagem dos museus tradicionais para conferir uma exterioridade poética ao livro e neste tocante, a instituição participa da elaboração de uma narrativa pertinente sobre o passado criativo do autor. Passado que confere estabilidade (identidade com o romance) ao lugar material de seus objetos, como o status simbólico destes, ao mesmo tempo em que dissolve as garantias entre os limites do real e da imaginação: "Sr Pamuk, tudo isso aconteceu realmente com o senhor? Sr. Pamuk, o senhor é Kemal?” (20I Ib, p. 29). 12

Todos estss exemplos pontuados apenas demonstram semelhanças no que tange ao discurso expográfico adotado pelos artistas e pelo museu de $\mathrm{Pa}$ muk e, como todas as aproximações teóricas, as condições e os estágios funcionam mais como expectativas do que como regras. As obras de arte do escritor - museu e romance - não se resumem, felizmente, à sua ideologia. $O$ romance termina com um bilhete impresso no final (Figura 12). A intenção é convidar todos os leitores a visitar o museu. Alguns críticos vão compreendê-la como simples estratégia de marketing. Porém, quase todas as histórias de Pamuk podem ser lidas como parábolas da inocência perdida ou de tentativas abortadas de redenção. $O$ museu do museu nos parece ser mais uma delas.

\section{Referências}

APPADURAI, Arjun. Entrevista com Arjun Appadurai a Bianca Freire Medeiros e Mariana Cavalcanti. Estudos Históricos, Rio de Janeiro, 20 I0,v. 23, n. 45, p. I87- 198. Disponível em: <http://www.scielo.br/scielo.php?script=sci_arttext\&pid=S0I 032 1862010000100009\&Ing=en\&nrm=iso>. Acesso em: nov. de 2012.

BENJAMIN, W. O colecionador. In: . Passagens. Belo Horizonte: UFMG; São Paulo: Imprensa Oficial do Estado de São Paulo, 2006. p. 237-247.

. Desempacotando minha biblioteca: um discurso sobre o colecionador. In: _. Obras escolhidas: a rua de mão única. São Paulo: Brasiliense, 1987. v. 2, p. 227-235.

CASTRO,Ana Lúcia Siaines de. O museu do sagrado ao segredo. Rio de Janeiro: Revan, 2009.

CERTEAU, Michel de.A beleza do morto. In: .A cultura no plural.Tradução Enide Abreu Dobránszky. Campinas: Papirus, 1995.

DERRIDA, Jacques. Mal do arquivo, impressões freudianas. Rio de Janeiro: Relume Dumará, 200I.

KENNEDY, J. Michael. Pamuk e a nostalgia. O Estado de São Paulo, São Paulo, 8 maio 2012. Caderno 2, D7.

MELENDI, Maria Angélica. O museu das insignificâncias: a memória, a arte e os restos da derrota. In: FLORES, M. B. R.; PATERIE, P. (org.). História e arte: imagem e memória. Campinas, SP: Mercado das Letras, 2012.

MENESES, Ulpiano T. B. de.Arquivos de artista, museus e pesquisa: reflexões de um historiador. In: MAGALHÃES, Ana Gonçalves (org.). Anais do Seminário In-

$12 \mathrm{~A}$ resposta do escritor pouco esclarece a questão colocada: "Permitam-me dar duas respostas contraditórias, nas quais acredito sinceramente: I. 'Não, eu não sou meu herói Kemal'. 2. 'Mas seria impossível convencer os leitores de meu romance de que não sou Kemal.” (PAMUK, 20 I lb, p. 30). 
ternacional Arquivos de Museus e Pesquisa. São Paulo: MAC/USP, 2010.

PAMUK, O. Istambul: memória e cidade. Tradução Sergio Flaksman. São Paulo: Cia das Letras, 2007.

.O livro negro. Tradução Sergio Flaksman. São Paulo: Cia das Letras, 2008. Letras, 20I la.

O Museu da Inocência.Tradução de Sergio Flaksman. São Paulo: Cia das

.O romancista ingênuo e sentimental. Tradução de Hildegard Feist. São Paulo: Cia das Letras, 20 I Ib.

POULOT, Dominique. O modelo republicano de museu e sua tradição. In: BORGES, Maria E. L. (org.). Inovações, coleções, museus. Belo Horizonte:Autentica, 201 I.

PUTNAM, James. Art and Artifact: the museum as medium. New York: Thames \& Hudson, 2009.

SCHULTZ, Deborah. Marcel Broodthaers: strategy and dialogue. Berna: Peter Lang, 2007.

TAYLOR, Brandon. The art of today. London:The Everyman Art Library, 1995. 